\title{
Positive impact on the environment of an outdoor sport
}

\author{
Inma Farran-Codina ${ }^{1}$, Pilar Silvente ${ }^{2}$ \\ 1 Inma Farran-Codina MD. PhD; Fundació Privada Ona Futura. Alcúdia. Mallorca. Illes Balears Spain \\ 2 Pilar Silvente; EDAR/EMSA Ajuntament d'Alcúdia. Mallorca. Illes Balears. Spain \\ * Correspondence inma.farran@onafutura.org; Tel.: +34 670971867
}

\begin{abstract}
The concept of sustainability applied to sports activities means ensuring that the economic benefits brought about by their development are not obtained at the expense of causing ecological damage or an interference in local cultural habits. A cable-ski is a nautical ski system whereby a motorboat is substituted by a cable traction system powered by an electric motor. The effect on the quality of the water in those places that can boast cable-ski facilities has been described in cold freshwater lakes. Objective: Our purpose was to study the evolution of water quality in a ten-year period after the installation of a cable-ski facility in a warm, salted, semi-stagnant pond. Material and Method: Review of the data gathered from the routine test carried out by the Laboratory of the Council of Alcúdia from 2010 to 2019 Results: The levels of dissolved oxygen have increased, being significantly higher in the period 2016 - 2019 than in that of $2010-2015$. The turbidity of the water has also seen a reduction in the second period with respect to the first. Conclusion: It seems that cable-ski improves the quality of water even warm, high-conductivity, semi-stagnant conditions
\end{abstract}

Keywords: 1: water quality; 2: outdoor sports; 3: dissolved Oxygen; 4: stagnant water; 5: cable ski.

\section{Introduction}

As a result of a sedentary lifestyle, stress and the pressure exerted on individuals in urban settings there has been an increase in the number of people taking up outdoor sports. And it is only to be expected that, after the confinement and restrictions imposed by the Covid 19 pandemic, we should see an even greater increase in outdoor sports activities.

A cable-ski is a nautical ski system whereby a motorboat is substituted by a cable traction system powered by an electric motor. This system was first used in Germany in 1959 and has since extended to Central Europe and the USA. It accommodates the classical forms of water skiing as well as "wake board" and water skating. The very design of the traction facilities provides not just training for beginners but the execution of advanced complex figures at greater heights by expert skiers.

The system is comprised of two cables united forming a rectangular or pentagonal circuit at a height of between five to eight metres above the water. The cables are guided by means of pulleys fixed to brackets which in turn hang from towers in the shape of a grid. The entire installation is powered by an electric motor of approximately sixty horsepower (HP). We are dealing with a sport in which the environmental impact is greatly reduced compared to conventional water skiing as the electric motor substitutes the fossil fuel used by the motor boats as well as eliminating noise pollution, the wave effect on the shoreline and any likelihood of fuel leakages. Much has been written about the effect on the quality of the water in those places that can boast ski cable facilities [1] [2] [3]. Most of these reports 
have come from Germany, from the cold freshwater lakes there; and have been provided by the main company manufacturing cable-ski systems. The increase in the oxygen in the water in those places with cable-ski facilities is thanks to the agitation of the water and the "splash effect" caused by the activity of the skiers increasing the contact surface between the water and the air.

In Alcúdia (Mallorca) there is a cable-ski facility situated in an artificial pond, part of a system of ponds and channels connected with the sea, which is characterized by the high temperature of the water, its state of semi stagnation and its elevated conductivity (salinity). Its depth ranges from 1,5 to $2 \mathrm{~m}$. The map is shown in Figure 1.

Our objective was to evaluate the evolution of the quality of water at the "Estany Petit" from the start of Wake-Park Mallorca in 2010 until now.

Figure1: S'Estany Petit Ponds and channels Alcúdia (Balearic Islands).

Google Maps (39.83534,3.10716).

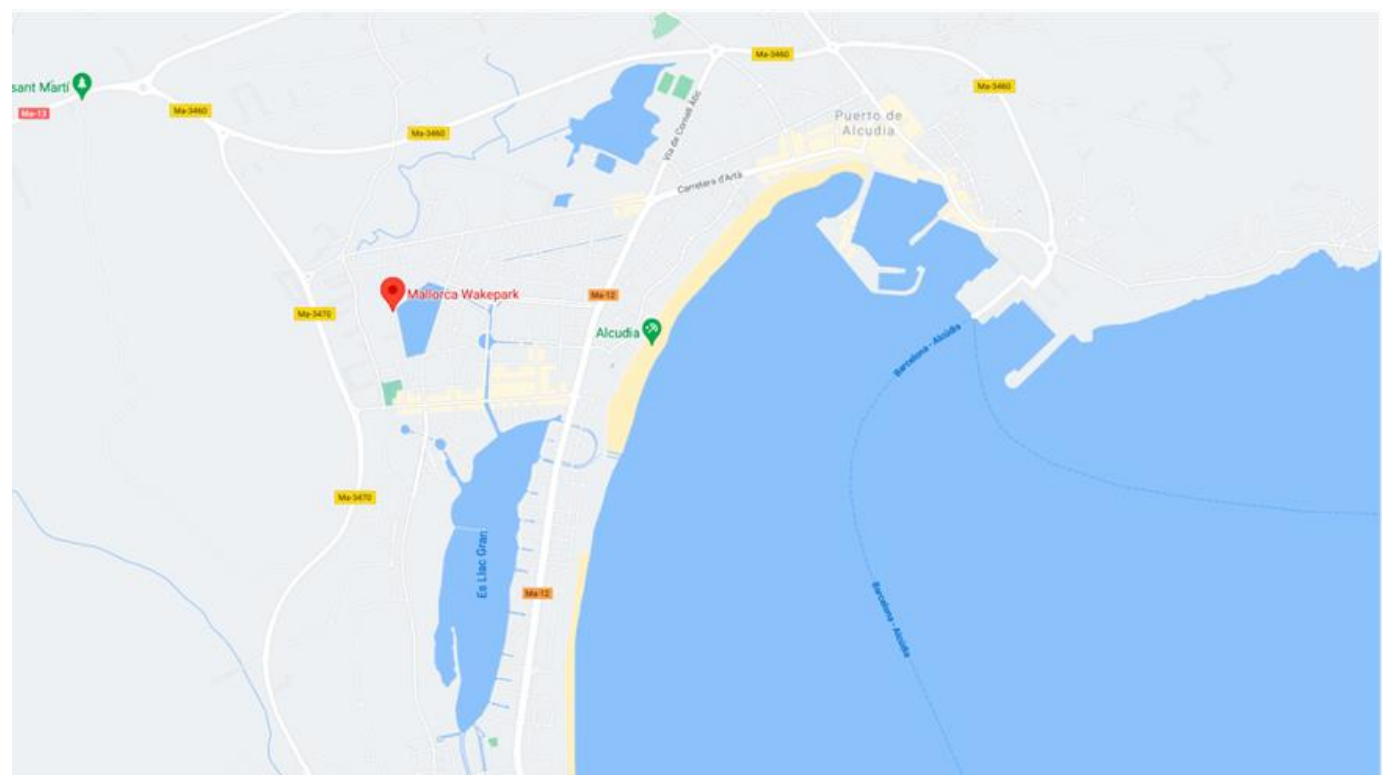

\section{Materials and Methods}

In collaboration with the Town Council of Alcúdia and availing ourselves of the data gathered from routine tests we analysed the evolution of the water from the "Estany Petit" through the period from the installation of Wake-Park Mallorca in 2010 to December 31st 2019. We decided not to include the measurements of the year 2020 because of two reasons, first: the pandemic changed dramatically the dynamics of the area, thus, the measurements could not to be representatives and, second: there were fewer controls than usual due to the lock-down.

Routine tests were done following the official regulations issued by the Government of the Balearic Islands. Samples were taken at 0,5 meters deep and measurement of $\mathrm{pH}$, dissolved oxygen, temperature, and conductivity were done using a portable $\mathrm{HQD}^{\mathrm{TM}}$ meter (HACH -Lange) HQ30D equipped with Intellical ${ }^{\mathrm{TM}}$ probes. 
Turbidity was evaluated by sediment concentration and sediment settling time and registered in a qualitative scale as: 1:"High turbidity"; 2: "Medium Turbidity"; 3: Low Turbidity"; 4: "Transparent" [4]

Statistic analysis was performed using standard tool Excel by Microsoft. For each one of the parameters analysed: Conductivity, dissolved oxygen, $\mathrm{pH}$, temperature, and turbidity, we show the results grouped by year, and grouped in two periods: 2010-2015 and 2016-2019. The reason was that the cable-ski activity started in July 2010, and we can consider that the theoretical effects during the first year could be minimum. In addition, the number of observations for each year ranges between 11 and 17, which gives greater reliability when groups with a greater number of observations are compared.

Results for conductivity, dissolved oxygen, $\mathrm{pH}$ and temperature were compared using Student's T-test, turbidity, as qualitative variable was evaluated using two-proportion ztest, level of statistical significance was fixed at $p$ value $<0.05$. Pearson's correlation coefficient was used to evaluate the existence of changes over time.

\section{Results}

\subsection{Conductivity}

Conductivity measured in $\mathrm{m}$ Siemens $(\mathrm{mS})$ as an indirect measurement of dissolved salts depends on the contribution of fresh water from rain or subsoil seepage. Due to high temperature in Mallorca during summer and the lack of rain, evaporation is the main reason for a higher conductivity during the summer months. (Figure.2).

Figure 2: Conductivity measurements 2010-2019.

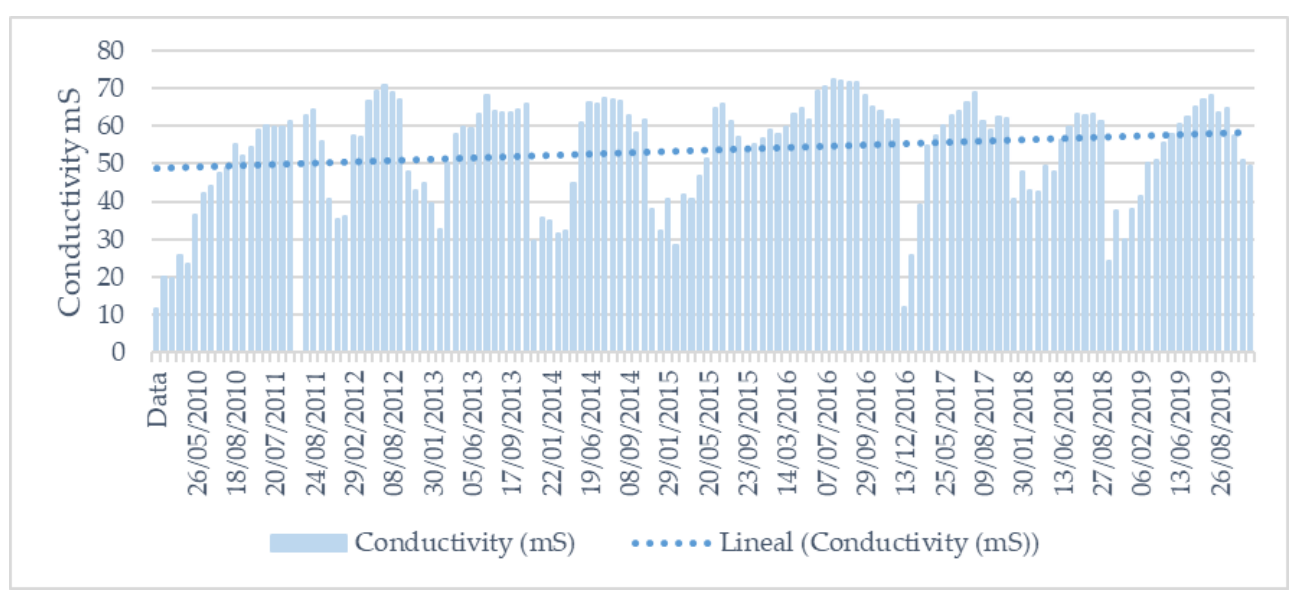

Table 1 shows the mean (๑), standard deviation (SD); Median (Me) Maximum and Minimum conductivity measured in $\mathrm{mS}$ for each year. There seem to be no big differences year to year, however, when the results are grouped in two groups from January 2010 to December 2015 and from January 2016 to December 2019 (Table 2), there is a clear increase in mean, and median conductivity (Student- $T$ test; $\mathrm{p}=0,022$ ) that is consistent with the tendency shown in the figure 1. $(r=0,1722)$. Table 2.Conductivity results (mS) in two consecutive periods.

Table 1: Annual Conductivity Results (mS) 2010-2019 


\begin{tabular}{lrrrrrrrrrr}
\hline & 2010 & 2011 & 2012 & 2013 & 2014 & 2015 & 2016 & 2017 & 2018 & 2019 \\
\hline N. Observations & 11 & 11 & 11 & 15 & 15 & 14 & 17 & 14 & 14 & 17 \\
Mean & 34,06 & 57,32 & 56,34 & 55,06 & 52,90 & 49,72 & 65,56 & 53,96 & 49,96 & 54,85 \\
SD & 14,54 & 6,65 & 13,72 & 12,65 & 14,67 & 11,68 & 5,03 & 16,63 & 11,80 & 10,83 \\
Median & 36,60 & 59,80 & 57,60 & 59,80 & 60,80 & 52,50 & 64,90 & 60,55 & 48,65 & 57,30 \\
Maximum & 55,10 & 64,40 & 70,90 & 68,20 & 67,40 & 65,80 & 72,40 & 68,80 & 63,30 & 68,20 \\
Minimum & 11,46 & 40,50 & 35,10 & 29,50 & 31,40 & 28,30 & 57,90 & 12,10 & 24,00 & 29,90 \\
\hline
\end{tabular}

Table 2: Conductivity results (mS) in two consecutive periods.

\begin{tabular}{lrr}
\hline & $2010-2015$ & $2016-2019$ \\
\hline N. Observations & 77 & 62 \\
Mean & 51,17 & 56,48 \\
SD & 14,37 & 12,69 \\
Median & 55,90 & 60,85 \\
Maximum & 70,90 & 72,40 \\
Minimum & 11,46 & 12,10 \\
\hline
\end{tabular}

\subsection{Dissolved Oxygen}

Dissolved Oxygen levels measurements showed a slow but progressive increase between 2010 and $2019(r=0,22)$ as shown in Figure 3 .

Figure 3: Dissolved Oxygen (mg/l) 2010-2019

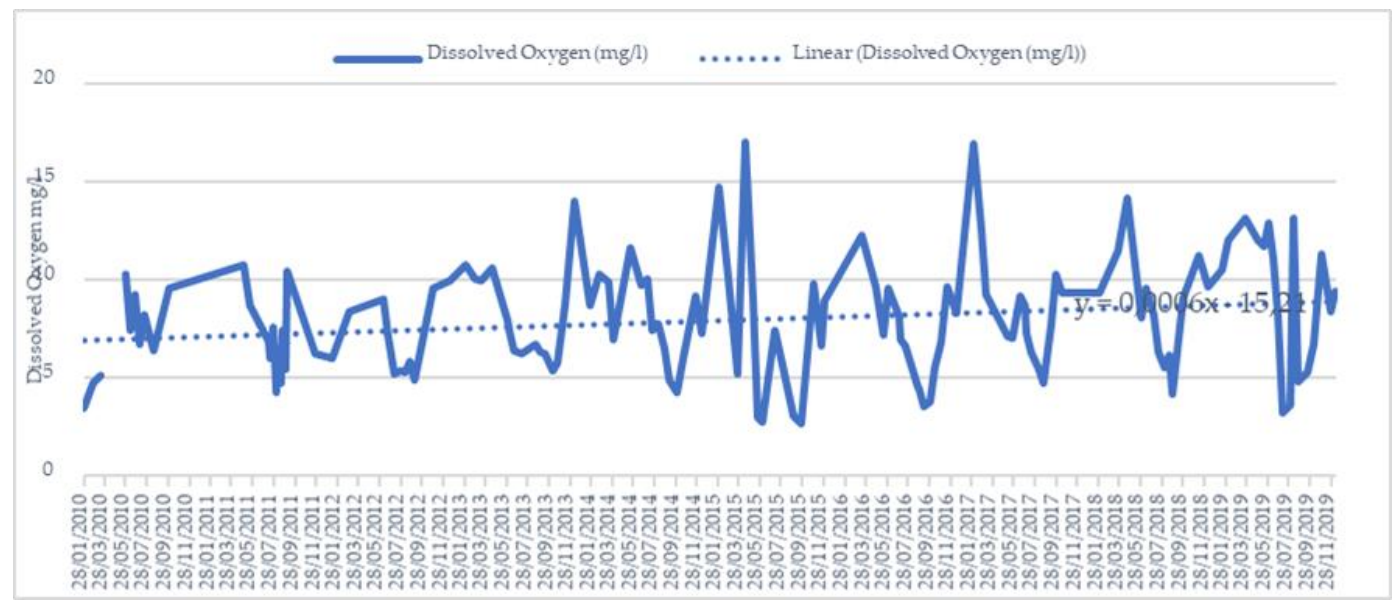

The increase in the oxygen levels per year is shown in Table 3. It seems much more linked to the increase in minimum levels than to the increase in maximum levels.

This impression is accentuated when the data are grouped in four-year periods, both: the mean and the median values showed an increase close to $1 \mathrm{mg} / 1$ in the period 2016-2019 when compared with the period 2010-2015; no significant differences in SD and maximum value determinate were observed, while the minimum value found was $0,55 \mathrm{mg} / \mathrm{l} \mathrm{higher}$ in the period 2016-2019 than the observed in the period 2010-205. $(p=0,04)$.

Table 3: Annual Dissolved Oxygen Results (mg/1) 2010-2019

$\begin{array}{llllllllll}2010 & 2011 & 2012 & 2013 & 2014 & 2015 & 2016 & 2017 & 2018 & 2019\end{array}$




\begin{tabular}{lrrrrrrrrrr}
\hline N. Observations & 10 & 12 & 11 & 15 & 15 & 14 & 17 & 14 & 14 & 17 \\
Mean & 7,12 & 7,04 & 6,98 & 8,18 & 8,05 & 7,61 & 7,49 & 8,72 & 8,85 & 9,28 \\
SD & 2,24 & 2,08 & 1,92 & 2,45 & 2,12 & 4,40 & 2,62 & 3,13 & 2,67 & 3,40 \\
Median & 7,07 & 6,57 & 5,98 & 7,44 & 7,75 & 7,02 & 7,19 & 8,22 & 9,21 & 10,50 \\
Maximum & 10,2 & 10,76 & 9,95 & 14,03 & 11,67 & 17,00 & 12,27 & 16,96 & 14,14 & 13,15 \\
& 9 & & & & & & & & & \\
Mínimum & 3,51 & 4,26 & 4,92 & 5,38 & 4,30 & 2,73 & 3,57 & 4,73 & 4,18 & 3,28 \\
\hline
\end{tabular}

Table 4: Dissolved Oxygen (mg/l) in two consecutive periods

\begin{tabular}{lrr}
\hline & $2010-2015$ & $2016-2019$ \\
\hline N. Observations & 77 & 62 \\
Mean & 7,56 & 8,56 \\
SD & 2,68 & 2,99 \\
Median & 7,29 & 8,36 \\
Maximum & 17,00 & 16,96 \\
Minimum & 2,73 & 3,28 \\
\hline
\end{tabular}

\subsection{Temperature}

No differences were observed in the water temperature pattern, both in the year by year analysis and in the one performed by grouping by periods as shown in Tables 5 and 6 . $(p=0,99)$

Table 5: Temperature ${ }^{\circ} \mathrm{C}$. Results year to year

\begin{tabular}{lrrrrrrrrrr}
\hline & 2010 & 2011 & 2012 & 2013 & 2014 & 2015 & 2016 & 2017 & 2018 & 2019 \\
\hline N. Observations & 9 & 12 & 11 & 15 & 15 & 14 & 17 & 14 & 14 & 17 \\
Mean & 22,57 & 26,46 & 23,74 & 21,86 & 21,68 & 20,49 & 22,02 & 23,94 & 22,79 & 22,08 \\
SD & 8,92 & 3,25 & 6,20 & 6,50 & 6,49 & 6,30 & 5,37 & 5,35 & 6,29 & 6,33 \\
Median & 26,00 & 27,45 & 27,70 & 23,30 & 24,70 & 20,60 & 23,00 & 24,85 & 25,25 & 23,40 \\
Maximum & 31,80 & 29,70 & 29,90 & 30,40 & 30,00 & 30,20 & 29,30 & 29,20 & 30,90 & 29,60 \\
Minimum & 10,90 & 20,10 & 14,60 & 10,40 & 10,30 & 10,90 & 13,70 & 13,30 & 12,10 & 9,90 \\
\hline
\end{tabular}

The average temperature observed each year is above $21^{\circ} \mathrm{C}$. Considering seasonal variations, these temperatures allow us to speak of "warm water" most of the year.

Table 6: Temperature ${ }^{\circ} \mathrm{C}$ in two consecutive periods

\begin{tabular}{lrr}
\hline & $2010-2015$ & $2016-2019$ \\
\hline N. Observations & 76 & 62 \\
Mean & 22,65 & 22,65 \\
SD & 6,44 & 5,76 \\
Median & 24,80 & 23,85 \\
Maximum & 31,80 & 30,90 \\
Minimum & 10,3 & 9,90 \\
\hline
\end{tabular}




\section{4. $p H$}

There were also no significant differences observed in the variations of the $\mathrm{pH}$ values year by year or in grouped periods of time. Results are shown in Table 7 and Table 8 respectively. $(p=0,199)$

Table 7: pH (pH Units). Results year to year

\begin{tabular}{lrrrrrrrrrr}
\hline & 2010 & 2011 & 2012 & 2013 & 2014 & 2015 & 2016 & 2017 & 2018 & 2019 \\
\hline N. Observations & 9 & 12 & 11 & 15 & 15 & 14 & 17 & 14 & 14 & 17 \\
Mean & 8,12 & 7,89 & 8,11 & 8,32 & 8,53 & 8,10 & 8,15 & 8,37 & 8,35 & 8,25 \\
SD & 0,23 & 0,48 & 0,29 & 0,16 & 0,34 & 0,57 & 0,19 & 0,28 & 0,20 & 0,24 \\
Median & 8,10 & 8,02 & 8,17 & 8,30 & 8,54 & 8,14 & 8,12 & 8,27 & 8,32 & 8,22 \\
Maximum & 8,52 & 8,37 & 8,33 & 8,71 & 9,16 & 8,90 & 8,50 & 8,91 & 8,73 & 8,64 \\
Minimum & 7,66 & 6,52 & 7,29 & 8,09 & 7,93 & 6,78 & 7,84 & 8,08 & 8,02 & 7,91 \\
\hline
\end{tabular}

Table 8: $\mathrm{pH}$ (pH Units) in two consecutive periods

\begin{tabular}{lrr}
\hline & $2010-2015$ & $2016-2019$ \\
\hline N. Observations & 76 & 62 \\
Mean & 8,20 & 8,27 \\
SD & 0,42 & 0,24 \\
Median & 8,21 & 8,26 \\
Maximum & 9,16 & 8,91 \\
Minimum & 6,52 & 7,84 \\
\hline
\end{tabular}

\subsection{Turbidity}

As mentioned at the materials and methods section, turbidity was measured in a four steps qualitative scale, from "High Turbidity "to "Transparent". Number of observations for each one of the categories year by year are shown in Figure 3 which includes a table with the number of observations.

In the same way as the other variables, we grouped the results in two time periods according to two categories" Murky", which includes high and medium turbidity and "Clear", which includes "Low Turbidity" and "Transparent". Results shown a clear increase in the number of "clear "samples as opposed to the number of "murky" samples during the second period of time $(Z: 3,32 ; p=0,00045)$, as it is shown in Figure 4.

Figure. 3: Turbidity. Number of observations by categories from year to year. 


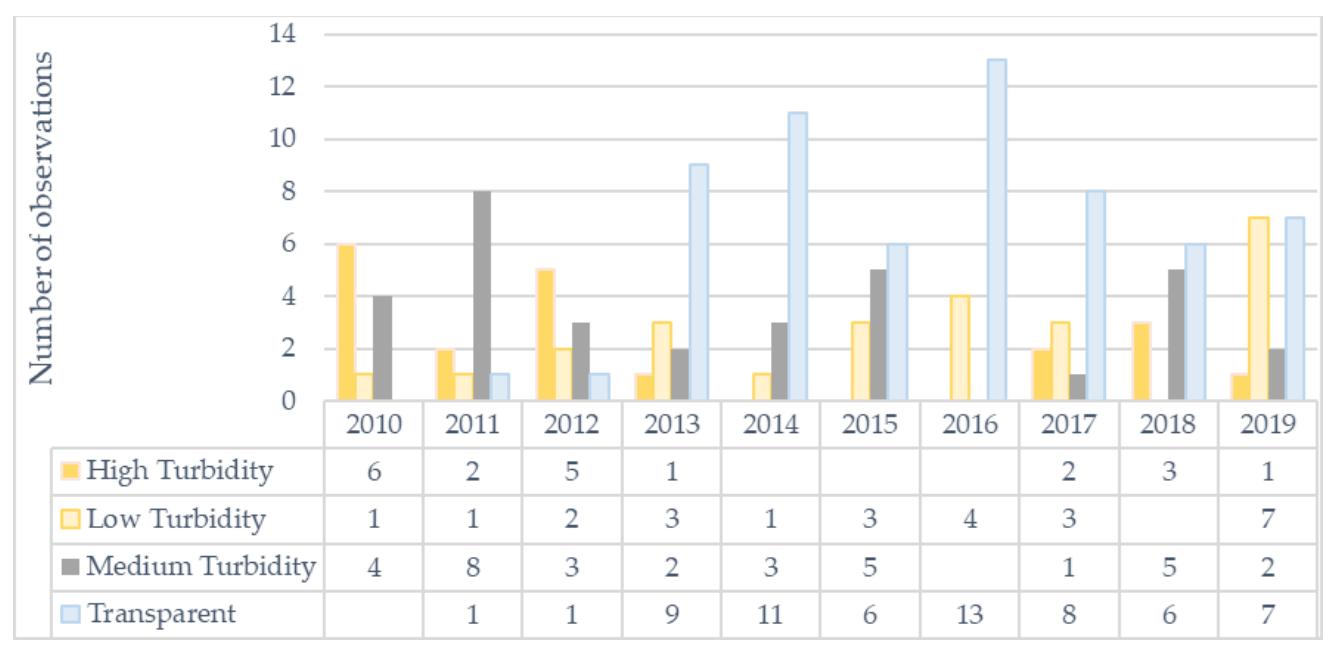

Figure. 4: Turbidity. Number of observations in two consecutive periods

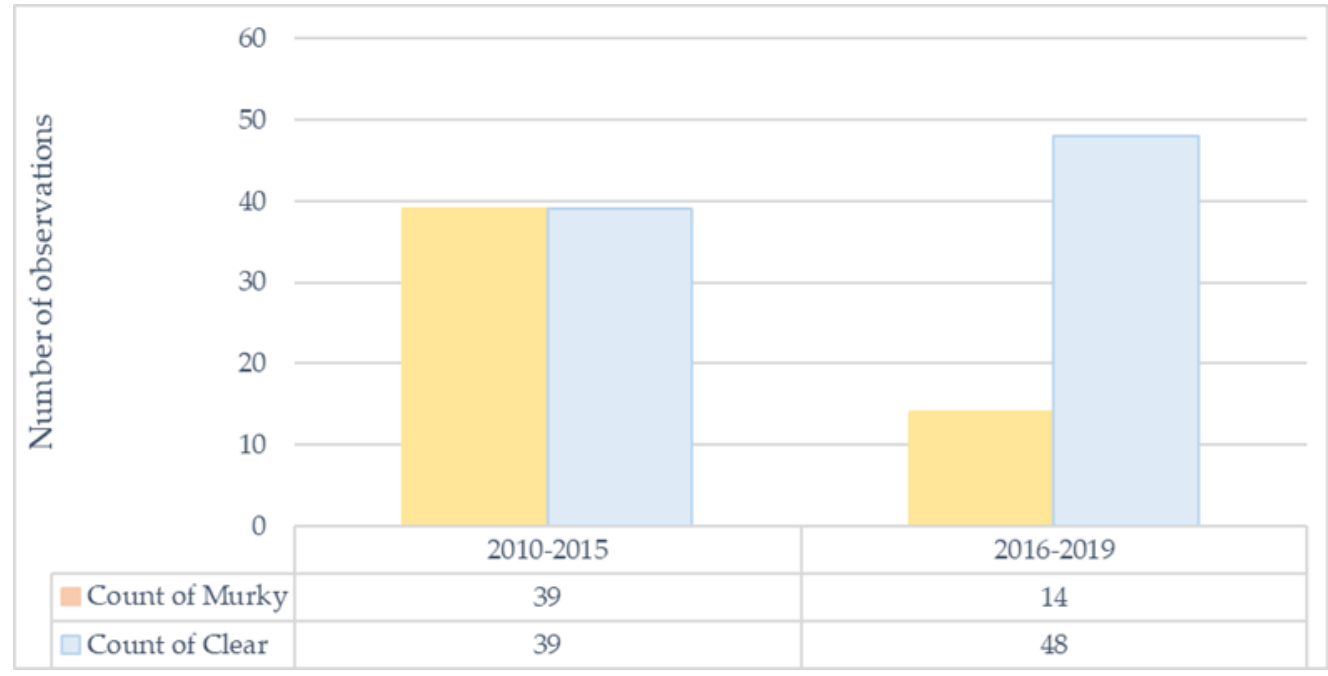

3.6 Relationship observed between conductivity, temperature, and dissolved oxygen.

Just as expected, there were no surprises in the negative relationship between conductivity and dissolved oxygen $(r=-0,42)$; positive relationship between conductivity and temperature $(\mathrm{r}=0,70)$, the correlation coefficient between temperature and dissolved oxygen was - 0,44 ; similar to that found when analysed conductivity.

The results changed when we analysed the levels of oxygen, temperature, and conductivity in relation to the period. (Figure 5)

Figure 5: Relationship between conductivity, temperature, and dissolved oxygen. 


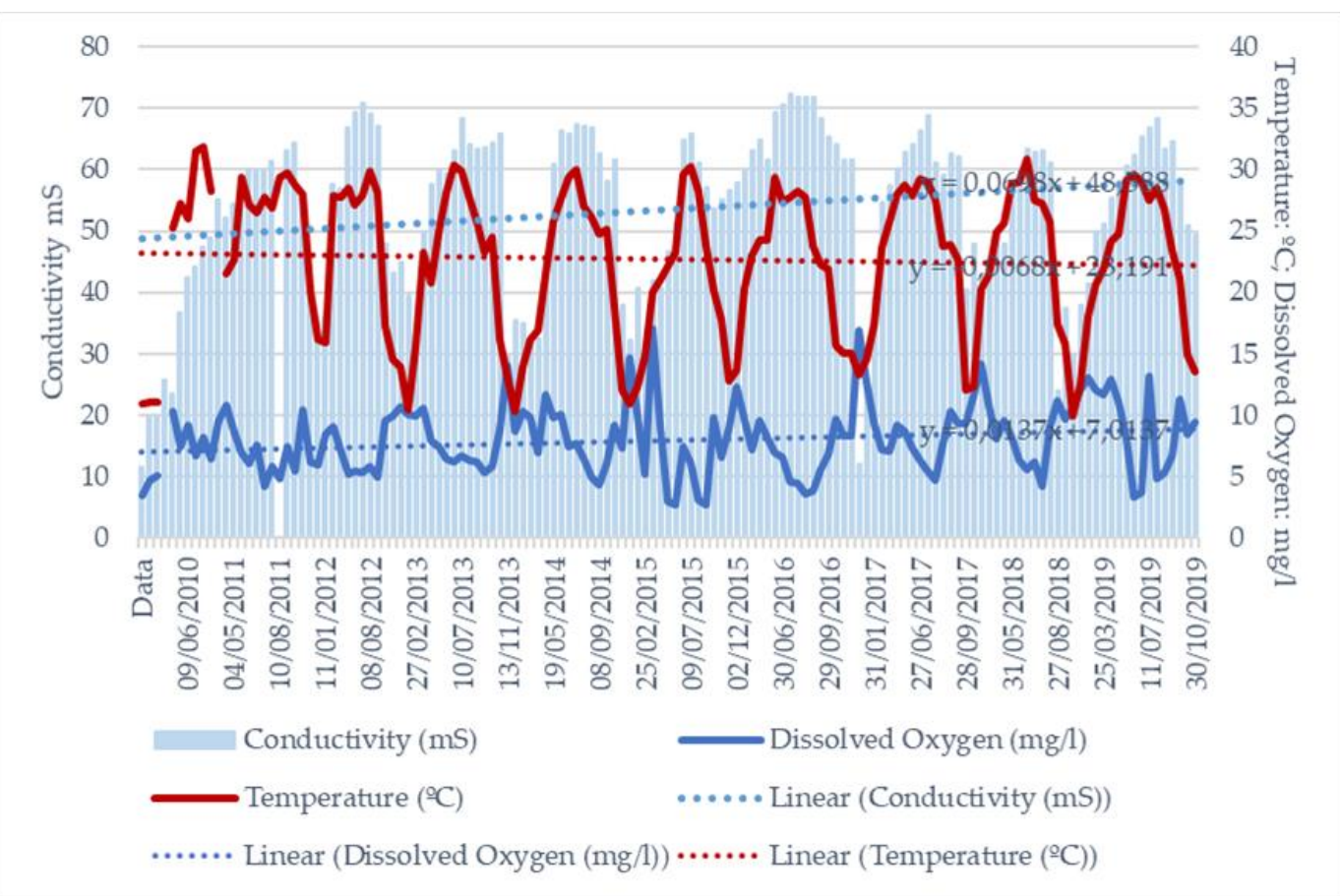

During the nine-year period, conductivity increased significantly as has been said in section 3.1, while the water temperature remained without significant changes. Despite these two findings, the levels of dissolved oxygen increased significantly too.

\section{DISCUSSION}

The concentration of dissolved gases in water is of prime importance in considering the quality of water. "S'Estany Petit" is placed at the sea level $(760 \mathrm{~mm} \mathrm{Hg})$. This pond is a part of an artificial system built in lands previously dried up for agricultural purposes and is a part of the remaining previous coastal lagoons. Water supplies are provided from rain, the Puig de Sant Martí springs, groundwater and the sea. Due to the low slope, the water circulation towards the sea is very slow, this fact favours the excessive growth of phytoplankton, mainly in summer. Additionally, the temperature of water and the high conductivity hampers the incorporation of oxygen into water [4]

The positive effects of the aeration of water are well known and have been widely applied [5] [6]. The providers of the cable-way system maintain that wakeboarding is a sustainable outdoor sport because it works without a boat, thus there are neither $\mathrm{CO} 2$ emissions, nor any "wave- effect" on the riverbanks or possible fuel leaks. In addition, they describe an improvement in the water quality by enriching the water with oxygen. The authors of this paper have not found any published references to the statements provided by the company that supplies the system [7]

The results obtained in s'Estany Petit in Mallorca show an increase of oxygen levels despite the increase of conductivity and the warm temperature of the water, both factors associated with difficulties in the incorporation of oxygen into water. It must be considered that the wake-park built in s'Estany Petit is a small one, that only allows one skier per circuit. The incorporation of oxygen into water is due to the "splash effect" of the board on the water, the more skiers the greater the effect. According to the providers of cable water ski systems, for every $\mathrm{kWh}, 1 \mathrm{~kg}$ of oxygen is incorporated into the water and they calculate that for 100 skiers per day, $200 \mathrm{~kg}$ of oxygen are incorporated every day; thus, $30 \mathrm{t}$ of oxygen are incorporated during a year if the cable-ski facility operates 150 days per year. [8]. 
We can suppose a low activity for the wake-park in the first year and an increasing number of visitors in the following ones. In any case, the average of skiers at s'Estany Petit has been calculated at 4.500 per year, an estimated number that is far below the 15.000 ones per year that are required for the incorporation of $30 \mathrm{t}$ oxygen.

The authors didn't have access to the exact number of cable-ski practitioners per year, but our estimate was very close to the real number in the second period (2016-2019). Applying the same calculation as that used by the providers, the total amount of oxygen incorporated per year is $8,5 \mathrm{t}$.

The increase in the incorporation of dissolved oxygen in stagnant waters modifies the environment in a way that favours repopulation by species that devour mosquito larvae, contributing to an improvement of the environment even in brackish and warm waters. It seems, therefore, that, due to the incorporation of oxygen into the water and the little impact on the environment, cable-ski could be one of the sustainable activities to provide decent income contemplated in the 2030 agenda adopted by the UN, that is being promoted by UNEP (the United Nations Environmental Programme).

To ensure that the improvement in the quality of the water is related to the activity developed, we started a new study comparing the same parameters in the channels and ponds of the system during the period 2016-2019. It involves the study of seven different points of control into the system. This study is currently ongoing.

\section{References}

[1] Rixen Cableway, «https://www.rixencableway.com/en/news/environmental-benefit.html,» 0208 2019. [En línea]. Available: https://www.rixencableway.com/en/news/.

[2] Rixen Cableway, «https://www.rixencableway.com/en/news/environmental-benefit-2.html,» 158 2019. [En línea]. Available: https://www.rixencableway.com.

[3] Rixen Cableway, «https://www.rixencableway.com/en/news/environmental-benefit-3.html,» 29 2019. [En línea]. Available: https://www.rixencableway.com.

[4] Departments of the Army and Air Force USA, «Technical Manual TM 5-813-3/AFM 88-10,Volume 3, Water Supply, Water Treatment,» Office of the Chief of Engineers. United States Army. US Government Printing Office, Washington DC, 1985.

[5] B. Liu, W. Wang, R. Han, M. Sheng, X. Du, X. Wu and W. G, "Dynamics of Disolved Oxygen and the Affecting Factors in Sediment of Polluted Urban Rivers under Areation Treatment," vol. 227, 2016.

[6] K. Resler, Sediment based turbidity analyses for representative South Carolina soils, Clensom, USA: Clemson Unversity, 2011. All Theses.1203.

[7] B. Breen, J. Curtis y S. Hynes, «Water quality and recreational use of public waterways,» Journal of Environmental Economics and Policy, vol. 7, no 1, pp. 1-15, 2018. 


\section{Author Contributions:}

Conceptualization, methodology; validation, formal analysis, investigation, resources, writingoriginal draft preparation, review and editing, visualization, supervision, project administration, funding acquisition, Inma Farran-Codina; data curation, Pilar Silvente

All authors have read and agreed to the published version of the manuscript.

Funding: This research received no external funding and it is a work proposed by the Fundació Ona Futura as a part of their mission.

Data Availability Statement: Data are public and available if are requested at Medi-ambient/Ajuntament d'Alcúdia mediambient@alcudia.net or to the authors.

Acknowledgments: The authors thank Mr. Xavier Campos, Dipl.Dolm. former United Nations officer, Mr. Terence Carty for their advice and Ms. Bàrbara Rebassa Mayor of Alcúdia for her support.

Conflicts of Interest: The authors declare no conflict of interest of the study; in the collection, analyses, or interpretation of data; in the writing of the manuscript, or in the decision to publish the results. 